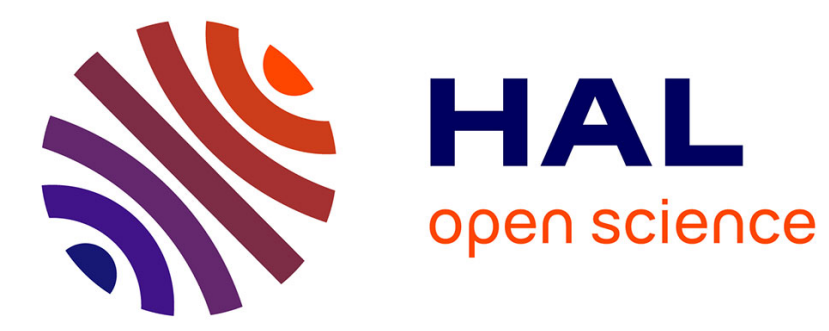

\title{
Quantifying virtual water scarcity risk transfers of energy system in China
}

Xuebing Yao, Xu Tang, Arash Farnoosh, Cuiyang Feng

\section{To cite this version:}

Xuebing Yao, Xu Tang, Arash Farnoosh, Cuiyang Feng. Quantifying virtual water scarcity risk transfers of energy system in China: Cahiers de l'Economie, Série Recherche, $n^{\circ} 139$. 2021. hal03206609

\section{HAL Id: hal-03206609 \\ https://hal-ifp.archives-ouvertes.fr/hal-03206609}

Preprint submitted on 23 Apr 2021

HAL is a multi-disciplinary open access archive for the deposit and dissemination of scientific research documents, whether they are published or not. The documents may come from teaching and research institutions in France or abroad, or from public or private research centers.
L'archive ouverte pluridisciplinaire HAL, est destinée au dépôt et à la diffusion de documents scientifiques de niveau recherche, publiés ou non, émanant des établissements d'enseignement et de recherche français ou étrangers, des laboratoires publics ou privés. 


\section{LES CAHIERS DE L'ÉCONOMIE}

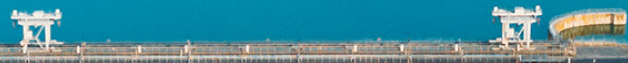

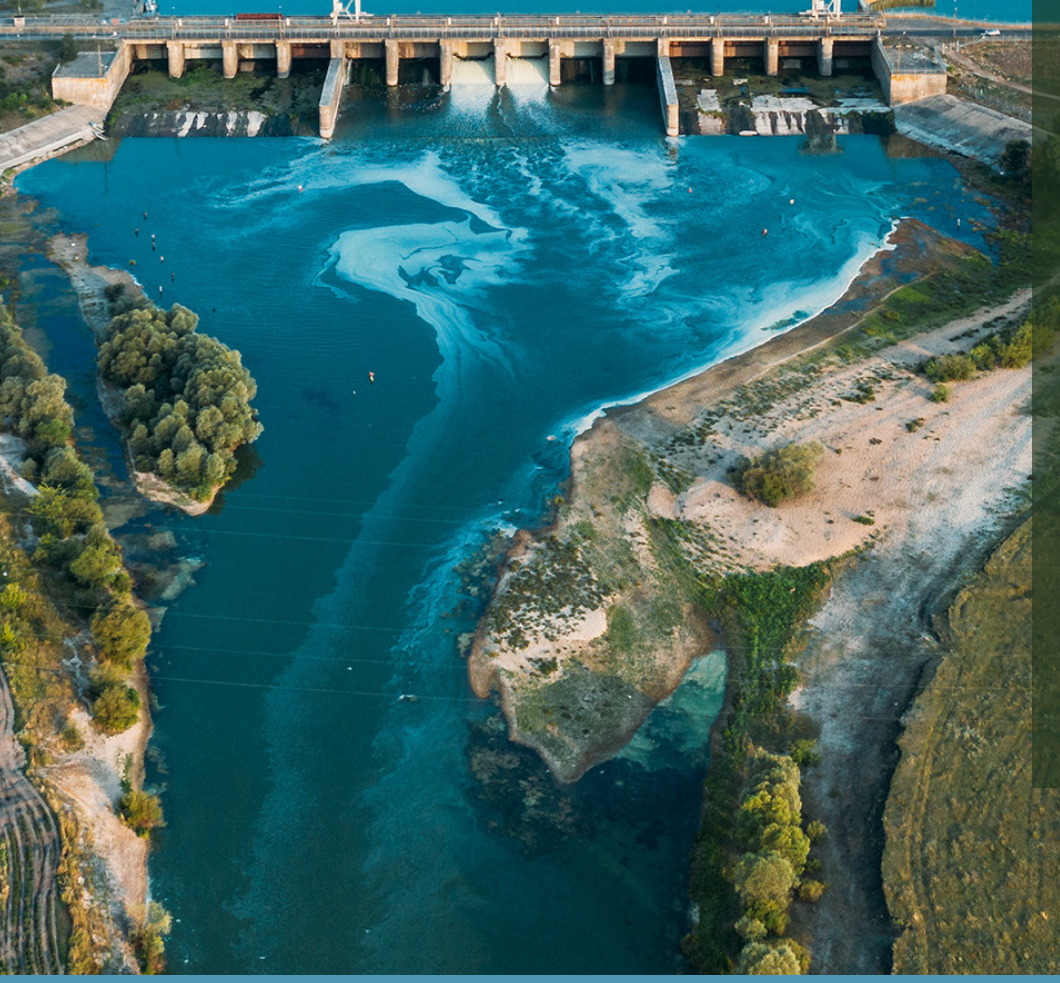

RECHERCHE

Q UANTIFYING VIRTUAL SCARCITY RISK TRANSFERS OF ENERGY SYSTEM IN CHINA

Using multi-regional input-output analysis, this study estimates the virtual flows ad virtual water scarcity risk transfers driven by interprovincial energy consumption in China. Results could provide reference value for policymakers to develop new energy strategies and manage water resources sustainably.

Xuebing Yao

Xu Tang

Arash Farnoosh Cuiyang Feng 
La collection "Les Cahiers de l'Économie" a pour objectif de présenter les travaux réalisés à IFP Energies nouvelles et IFP School qui traitent d'économie, de finance ou de gestion de la transition énergétique. La forme et le fond peuvent encore être provisoires, notamment pour susciter des échanges de points de vue sur les sujets abordés. Les opinions exprimées dans cette collection appartiennent à leurs auteurs et ne reflètent pas nécessairement le point de vue d'IFP Energies nouvelles ou d'IFP School. Ni ces institutions ni les auteurs n'acceptent une quelconque responsabilité pour les pertes ou dommages éventuellement subis suite à l'utilisation ou à la confiance accordée au contenu de ces publications.

Pour toute information sur le contenu, contacter directement l'auteur.

The collection "Les Cahiers de l'Économie" aims to present work carried out at IFP Energies nouvelles and IFP School dealing with economics, finance or energy transition management. The form and content may still be provisional, in particular to encourage an exchange of views on the subjects covered. The opinions expressed in this collection are those of the authors and do not necessarily reflect the views of IFP Energies nouvelles or IFP School. Neither these institutions nor the authors accept any liability for loss or damage incurred as a result of the use of or reliance on the content of these publications.

For any information on the content, please contact the author directly.

\title{
Pour toute information complémentaire For any additional information
}

\author{
Victor Court \\ IFP School \\ Centre Economie et Management de l'Energie \\ Energy Economics and Management Center \\ victor.court@ifpen.fr \\ Tél +33147527317
}




\title{
Quantifying virtual water scarcity risk transfers of energy
}

\section{system in China}

\author{
Xuebing Yao ${ }^{\mathrm{a}}, \mathrm{Xu}$ Tang $^{\mathrm{a}}$, Arash FARNOOSH ${ }^{\mathrm{b}}$, Cuiyang Feng ${ }^{\mathrm{c}}$ \\ ${ }^{a}$ School of Economics and Management, China University of Petroleum, Beijing 102249, China \\ 'bFP Energies Nouvelles, IFP School, 232 Avenue Napoléon Bonaparte, 92852 Rueil-Malmaison \\ Cedex France \\ ${ }^{\mathrm{c}}$ State Key Joint Laboratory of Environment Simulation and Pollution Control, School of \\ Environment, Beijing Normal University, Beijing, China
}

\begin{abstract}
Water scarcity problem has become a major constraint in energy development. In this paper, we calculated virtual water flows and virtual water scarcity risk transfers driven by interprovincial energy consumption in China by using multi-regional input-output analysis. The results of virtual water scarcity risk transfers show that major virtual water scarcity risk importers will be the "victims" suffering the consequences of increasing virtual water scarcity risks in national energy system. For major virtual water scarcity risk exporters, they will transfer virtual water scarcity risks to downstream provinces along energy supply chains, threatening the stability of national energy system. The promotion of energy policies and the energy consumption of developed regions make the water-deficient northwest regions export a large amount of water resources to the east and south regions. Therefore, it is necessary to fully consider local water scarcity and evaluate the impact on water environment before construction of energy bases. Our findings can be used to provide reference value for policymakers to develop new energy strategies and manage water resources sustainably.
\end{abstract}

Keywords: virtual water scarcity risk; water footprint; energy consumption; multi-regional input-output analysis

\section{Introduction}

Water is an indispensable resource for economic and social development(Lee, et al., 2019, Distefano and Kelly, 2017). With the economic development and population growth, the water demand is increasing day by day, while the shortage of fresh water and water pollution problems are getting worse. Water shortage will be an important challenge for all countries around the world in the future(Distefano and Kelly, 2017). Due to high-speed growth of its economy and population, China is facing a 
particularly serious water shortage problem(Cai, et al., 2017, Fan, et al., 2019).

To address the uneven distribution of water resources, in addition to build large-scale physical water transfer projects(Zhao, et al., 2015, Sun, et al., 2018), there is another solution, which is virtual water flows. The concept of virtual water refers to the total amount of water resources needed in the process of production and consumption of products or services(Liu and Yang, 2012). The process of transferring goods through interregional trade is also the process of virtual water flowing between different regions along the supply chain, namely virtual water flows(Zhang and Anadon, 2014). By using virtual water flows, local water resources can be protected through importing water-intensive products or services rather than producing it locally(Chen, et al., 2018).

But existing studies found that the virtual water transfer did not play an important role in virtual water import regions. On the contrary it exacerbated water shortage problems in virtual water export regions(Zhao, et al., 2015, Wang, et al., 2018, Zhang, et al., 2019). Cai, et al. (2019) calculated virtual water flows in China from 2002 to 2012 and found that the direction of virtual water flows was reversed. Northwest and northeast regions became the main virtual water export regions. Among the inter-provincial virtual water flows, the share of agriculture, power sectors, and chemical industries accounted for more than $83 \%$. The contradiction between the direction of virtual water flows and the distribution of water resources will deepen with the rapid economic development. The production and consumption of energy is one of the main drivers causing the contradictory direction of virtual water flows in China.

The energy sectors are highly dependent on water supplies. According to World Energy Outlook 2016(IEA, 2016), the water withdrawal of energy production and consumption accounts for $10 \%$ of global total water withdrawal, which is mainly used for power generation and primary energy production. When facing water shortages, energy sectors will be more likely to be seriously threatened(Sun, et al., 2018). According to the IEA, in 2018, China's total primary energy consumption ranks the first in the world(IEA, 2019). With the rapid development of China's economy, China's energy demand will continue to increase in the future(IEA, 2020). In order to cope with the growing energy demand, government plans to increase investment on the energy supply side and builds nine large-scale 10 gigawatts coal-fired power bases in Xinjiang, Inner Mongolia, Ningxia, Shanxi, Shaanxi(Shang, et al., 2016). But these coal-rich regions are concentratedly located in the north and northwest, because of 
water shortages there were several planned coal-to-liquid(CTL) plants abandoned(Qin, et al., 2015). The relationship between energy and water is a major and important challenge(Feng, et al., 2019, Tang, et al., 2018).

The existing studies on water consumptions of energy sectors mainly focus on the analysis of water consumption in thermal power plants dominated by coal fuels(Larsen and Drews, 2019, Bravo, 2016). Qin, et al. (2015) used bottom-up approach to account the water withdrawal of various links in the production process of energy sectors in China. They found that if the existing energy sectors' production technologies stayed unchanged, only the water withdrawal of coal-fired power plants will exceed the industrial water usage targets in water policy. Existing studies have analyzed the water usages of power sector's production and consumption from different perspectives, including regional economies(Larsen and Drews, 2019), country level(Chini, et al., 2018), sub-national regions(Sun, et al., 2018). Liao, et al. (2019)accounted the water consumption of energy sectors in China's two major economic belts, the Jing-Jin-Ji Economic Belt and the Yangtze River Delta Economic Belt. They found that the water footprint of electricity consumption accounts for the largest proportion of all energy products. They also found that the energy production and supply of these two major economic belts aggravated local water shortage problems which will be worsened by the growing demand for energy.

In the researches of accounting water footprint of energy sectors, there are two main accounting methods. First one is the bottom-up method, which refers to calculating water consumption of each link in the process of production(Liao, et al., 2016). The bottom-up method is mainly used under the high-resolution data condition, without considering the inter-regional trade linkages. It cannot cover the interconnection and heterogeneity of different regions in the economy. Another approach is the input-output analysis. Input-output analysis is a top-down approach originally developed by Leontief (1970). It relies on the classification of national economic sectors in the input-output table, combined with environmental factors, to calculate the environmental impact on all economic sectors (Zhang and Anadon, 2014, Dong, et al., 2019). Liao, et al. (2018)used multi-regional input-output analysis to calculate the water consumption in thermoelectric and hydropower plants in China. They found that almost half of the physical water inputs into the power sector were virtually transferred across provincial boundaries in the form of virtual water embodied in the electricity produced, mainly from provinces in northeast, central and south China to those in east and north China. Zhang, et al. (2017)calculated the virtual 
water and scarcity-adjusted virtual water embodied in the electricity transmission network in China. They realized that many ongoing long-distance electricity transmission projects will enlarge the scale of scarce water outflows from northwestern regions and increase their water stress.

Because of different water stresses in different regions, same quantity of water used in water-abundant regions does not pose the same risks to human health and ecosystem quality as that in water-scarce regions. Compared with water abundance regions, water scarce regions are more likely to confront serious water scarcity risks(Lee, et al., 2019, Ridoutt, et al., 2018). Existing studies showed that water scarcity has become an important constraint factor that cannot be ignored in energy development(Sun, et al., 2018, Zhang, et al., 2017). But there is little research on how water scarcity affects the energy system and to what extent. Qu, et al. (2018) quantified the water scarcity risks (the potential economic losses caused by water shortages) in the global trade system and found that virtual water scarcity risk export countries will spread potential economic losses to downstream countries along supply chain. And the geographical separation between countries where water shortages occur and countries where suffer the risk of economic losses is increasing.

Based on the summary of existing researches, we observe that most studies are mainly concentrated on calculating water usage from energy production side and there is a lack of research on water scarcity problem as an important limiting factor for energy development. Therefore, we find that the following three issues needed to be further discussed: (1) In energy consumption water footprint, how energy consumption drives the virtual water transfer among provinces; (2) Since water stresses vary from region to region, how to measure the impact of water scarcity on the energy system and the difference of water scarcity risks caused by energy consumption to different regions; (3) What are the transfer paths of virtual water scarcity risks caused by energy consumption. The answers to the above questions will help to further reveal how the water scarcity affects local energy systems and the transfer paths of virtual water scarcity risks. Therefore, this paper will use a multi-regional input-output analysis and take the water scarcities of different regions into consideration, to study the inter-provincial virtual water scarcity risk transfers caused by energy consumption in China.

\section{Methods and data}

In the input-output analysis, there are two main frameworks for calculating water footprint: one is the 'water embodied in trade' (WET) formed by referring to the 
'emissions embodied in bilateral trade' (EEBT); another is the multi-regional input-output (MRIO) analysis. The two calculation methods mainly differ in the allocation treatment of the intermediate uses in MRIO table(Peters, 2008). In WET, the intermediate uses are combined and reallocated to final demand(Zhao, et al., 2015, Cai, et al., 2019). In MRIO, the inter-regional intermediate uses and final demand are separated. Consequently, it can be used to track the whole flows of environmental effect factor in economy supply chain, where the flows are driven by final consumption. The MRIO framework is in line with the objectives of this paper and is introduced hereafter.

\subsection{Multi-regional input-output (MRIO) model}

In MRIO model, the basic balance is that total output is equal to total immediate uses plus final demand. It is assumed that there are $m$ regions and each region has $n$ sectors.

$$
x_{i}^{r}=\sum_{k=1}^{m} \sum_{j=1}^{n} a_{i j}^{r s} x_{j}^{s}+\sum_{k=1}^{m} y_{i}^{r s}
$$

Where $x_{i}^{r}$ represents the total output of sector $i$ in region $r ; y_{i}^{r s}$ represents the total final demand of region $s$ provided by sector $i$ in region $r ; a_{i j}^{r s}$ is direct requirement coefficient, which represents the input from sector $i$ in region $r$ directly required to produce unitary output of sector $j$ in region $s$, which can be calculated as follows:

$$
a_{i j}^{r s}=\frac{z_{i j}^{r s}}{x_{j}^{s}}
$$

Where $z_{i j}^{r s}$ represents the purchases of goods or services in sector $j$ in region $s$ provided by sector $i$ in region $r$; $x_{j}^{S}$ represents the total output of sector $j$ in region $s$.

$$
A=\left[\begin{array}{ccc}
\left(\begin{array}{ccc}
a_{11}^{11} & \ldots & a_{1 n}^{11} \\
\ldots & \ldots & \ldots \\
a_{n 1}^{11} & \ldots & a_{n n}^{11}
\end{array}\right) & \ldots & \left(\begin{array}{ccc}
a_{11}^{1 m} & \ldots & a_{1 n}^{1 m} \\
\ldots & \ldots & \ldots \\
a_{n 1}^{1 m} & \ldots & a_{n n}^{1 m}
\end{array}\right) \\
\left(\begin{array}{ccc}
a_{11}^{m 1} & \ldots & a_{1 n}^{m 1} \\
\ldots & \ldots & \ldots \\
a_{n 1}^{m 1} & \ldots & a_{n n}^{m 1}
\end{array}\right) & \ldots & \left(\begin{array}{ccc}
a_{11}^{m m} & \ldots & a_{1 n}^{m m} \\
\ldots & \ldots & \ldots \\
a_{n 1}^{m m} & \ldots & a_{n n}^{m m}
\end{array}\right)
\end{array}\right]
$$

Then equation (1) can be expressed in matrix form as follows:

$$
X=(I-A)^{-1} \cdot Y
$$


Where $(n \times m) \times 1$ column vector $X$ represents the total output of an economy; $(n \times m) \times 1$ column vector $Y$ represents the total final demand of products; $(n \times m) \times(n \times m)$ matrix $(I-A)^{-1}$ is the Leontief reverse matrix.

When considering water intensity, the water footprint can be expressed as:

$$
W F=W \cdot(I-A)^{-1} \cdot Y
$$

Where $W$ represents the water intensity for unitary output of each sector, it can be calculated as follows:

$$
w_{i}^{r}=\frac{v_{i}^{r}}{x_{i}^{r}}
$$

where $v_{i}^{r}$ represents the volume of water withdrawal in sector $i$ in region $r$.

In the calculation of this paper, the range of region $r$ is 30 provinces in China, the range of sector $i$ is the four energy sectors in the MRIO table: Coal mining (No. 2), Petroleum and gas (No. 3), Petroleum refining, coking, etc. (No. 11), Electricity and hot water production and supply (No. 22).

\subsection{Water scarcity risk model}

In order to measure the impact of water scarcity on energy systems, in this paper we calculate and evaluate the virtual water scarcity risks of China's energy system from energy consumption perspective. This is done by referring to the water scarcity risk model of $\mathrm{Qu}$, et al. (2018), where water scarcity risk refers to the potential risk of losses to regional economic output due to worsening water scarcity problems.

The water scarcity risk model aims to measure when the water scarcity problem worsens by one percentage, what amount of water supply in the regions will decrease due to water shortage and to what extent it will cause the loss of economic output of energy sectors. The Water scarcity risk model consists of two parts: Water Deprivation Risk (WDR) and Water Dependency (WD).

\subsubsection{Water Deprivation Risk (WDR)}

Water deprivation risk is used to measure the "deprived part" of the water supply used in the energy sectors caused by water scarcity. Water stress index (WSI) is widely used to assess the water stresses in regions. It refers to the ratio of the amount of water consumption to the total amount of water available in a region. Due to the quantity of available water in various regions is varied differently, each region has different WSIs. It will be lack of comprehensiveness only using WSI to evaluate the water scarcity of different regions. For regions with high WSIs, when water supply decreases, the regions' economy will not necessarily be affected. Even if the region's WSI is close to 1 or greater than 1 , in order to meet the water usage demand, the regions could continue to extract and use the limited local water resources. In the case 
of not considering the environmental impact, they could even "squeeze" the scarce water resources. Therefore, only from the perspective of WSI, it is impossible to compare the impact of the worsening water scarcity on energy sectors in different regions.

In order to make regions with different WSIs comparable, WSI is transformed into water deprivation risk (WDR) by a probability function. WDR can quantify the amount of water supply reduction due to water scarcity in regions. The ratio of total volume of available water resources to the volume of water consumption in region $r$ is regarded as a random variable $X^{r}$, assuming that the random variable $X^{r}$ follows a lognormal distribution, the expected value is the ratio of total volume of available water resources to the volume of water consumption in region $r$, namely the reciprocal of the WSI in region $r$. If random variable $X^{r} \geq 1$, the water supply of region $r$ can meet the local water demand; If random variable $X^{r}<1$, then the percentage of water deprivation in region $r$ is $\left(1-X^{r}\right)(\mathrm{Qu}$, et al., 2018).

$$
\begin{gathered}
\text { WDR } R^{r}=f_{W D R}\left(W_{\left.S I^{r} ; \sigma\right)=E\left[Y^{r}\right],}, \begin{array}{ll}
0 & \text { if } X^{r} \geq 1 \\
1-X^{r} & \text { if } X^{r}<1^{\prime}
\end{array}\right. \\
X^{r} \sim \operatorname{Lognormal}\left(\mu^{r}, \sigma\right) \\
\mu^{r}=\log \frac{1}{W S I^{r}}
\end{gathered}
$$

Where $W D R^{r}$ represents the water deprivation risk of region $r$, which is in the interval $[0,1] ; f_{W D R}\left(W S I^{r} ; \sigma\right)$ is a function based on probability to estimate $W D R^{r}$, parameter $\sigma$ is used to adjust and limit the heterogeneity in different regions; $W S I^{r}$ represents the ratio of volume of water consumption to total volume of available water resources in region $r$. By analyzing and adjusting the value of parameter $\sigma$, sensitivity analysis results were obtained (seen as Fig. A1), the results of $\sigma=1$ is selected to be the final results. To avoid the low WSI resulting in high water scarcity risk due to higher economic output, when $W S I^{r}<0.05$, we set $W D R^{r}=0$.

\subsubsection{Water Dependency (WD)}

The water dependency measures the potential risks of sectors' output losses when its water supply is reduced. Water Intensity (WI) refers to the volume of water consumption of sector's unitary output. Due to the different water stresses in each province and different water intensities in each sector, it is necessary to transform the different values of each region's indicator through water scarcity risk model to dimensionless values. In order to measure the dependency of different sectors on water supply, WI is transformed into the water dependency (WD) by using a logistic 
function $f_{W D}$ and a critical value $\alpha$. If sector's WD equal to the maximum value 1, in this case, it means water usage in this sector is completely irreplaceable and its output must be reduced in proportion to the water supply reduction. The calculation formula of water dependency is as follows $(\mathrm{Qu}$, et al., 2018).

$$
W D_{i}^{r}=f_{W D}\left(W I_{i}^{r} ; \alpha\right)=\frac{1}{1+e^{-\left(\frac{1}{0.001}\right) W I * \alpha}\left(\frac{1}{0.001}-1\right)}
$$

Where $W D_{i}^{r}$ represents the water dependency of energy sector $i$ in region $r$, which is in the interval $[0,1)$; parameter $\alpha$ is used as a critical value to control the saturation value of WI when WD is rapidly approaching 1. According to the sensitivity analysis obtained by adjusting the value of parameter $\alpha$ (seen as Fig. A2), the results of $\alpha=0.5$ is selected to be the final results.

After obtaining the WDR and WD, combined with energy sectors' benchmark output, which is the output without considering the impact of water scarcity, the calculation formula of local water scarcity risk can be obtained as follows $(\mathrm{Qu}$, et al., 2018).

$$
L W S R_{i}^{r}=W D R^{r} \times W D_{i}^{r} \times x_{i}^{r}
$$

Where $L W S R_{i}^{r}$ represents the local water scarcity risk of sector $i$ in region $r$; $W D R^{r}$ represents the water deprivation risk of region $r$, measuring the portion of reduction in water supply as a result of worsening water scarcity; $W D_{i}^{r}$ represents the water dependency of energy sector $i$ in region $r$, measuring the percentage of output losses due to one percentage reduction of water supply in energy sector $i$ of region $r ; x_{i}^{r}$ represents the benchmark output of energy sector $i$ in region $r$.

Under the close connection of inter-provincial energy trading in China, it is not comprehensive enough to consider only the direct local economic damage caused by water shortage in a certain region. Therefore, the water scarcity risk model is combined with MRIO model. The energy trade flows of all provinces in China are taken into consideration. This will help to analyze the virtual water scarcity risk transfers caused by energy consumption in the whole economy and to identify the key regions in the virtual water scarcity risk transfer network. By combining direct water scarcity risks with Leontief inverse matrix, the virtual water scarcity risks driven by energy consumption can be obtained. The calculation formula of virtual water scarcity risks is as follows.

$$
\begin{gathered}
W S R=\operatorname{diag}\left(\frac{L W S R}{X_{j}}\right) \cdot(I-A)^{-1} \cdot Y \\
V W S R_{i m_{i j}}^{r s}=\sum_{i \neq j} W S R_{i j}^{r s}
\end{gathered}
$$




$$
V W S R_{e x_{j i}}^{s r}=\sum_{j \neq i} W S R_{j i}^{s r}
$$

Where WSR represents the virtual water scarcity risks caused by energy consumption; $V W S R_{i m}{ }_{i}^{s r}$ represents the virtual water scarcity risks imported by region $s$ from energy sector $i$ in region $r$, unit $\mathrm{CNY} V W W S R_{\text {ex }}{ }_{i}^{r s}$ represents the virtual water scarcity risks exported by energy sector $i$ in region $s$ to region $r$, unit CNY.

\subsection{Data sources and treatment}

In this paper the data is mainly divided into two categories: one is China multi-regional input-output table (abbreviated as China MRIO table), the other is water usage data. Since National Bureau of Statistics releases the China input-output table every 5 years, the latest China MRIO table which can be obtained is year 2012 . In this study the 2012 China MRIO table was adopted from Mi, et al. (2017), which covers 30 provincial areas and 30 sectors of each province. The 30 provincial areas include 22 provinces, 4 megacities (Beijing, Tianjin, Shanghai and Chongqing) and 4 autonomous regions. All the 30 provincial areas are called provinces in this paper. Tibet, Taiwan, Hongkong and Macau are not included due to lack of data availability.

In order to consistent with China MRIO table, the water usage data of each sector in different province is collected and processed as follows.

a) The agriculture water withdrawal data of each province is collected from "China Statistical Yearbook 2013" (National Bureau of Statistics of China, 2013).

b) Due to the lack of detailed sectorial breakdown water usage data for all provinces, for industrial sectors, the latest available detailed data can be collected from "China Economic Census Yearbook 2008" (National Bureau of Statistics of China, 2010). Assuming that water intensity of each industry sector remains unchanged, water intensity of each industry sector is calculated based on the water withdrawal data in 2008. Because the water withdrawal data given in the "China Economic Census Yearbook 2008" were only for the industrial enterprises above the designated size, the water withdrawal data for each industrial sector is adjusted according to the total water withdrawal data of industrial in "China Statistical Yearbook 2013", under the assumption that water price of industrial sectors is the same.

c) As for construction, there is no directly statistical data on the water usage 
data of construction sector in each province of China, it is assumed that water intensity of construction sector of each province is the same as national average level. The water usage data for construction was collected from "First National Water Census Bulletin 2013" (Ministry of Water Resources, 2013).

d) For the water usage data of tertiary industry sectors, in the "China Water Bulletin 2012" (Ministry of Water Resources, 2013), the quantity of water for public service includes water usage for construction sector and water usage for tertiary industry sectors. Therefore, we used the quantity of water for public service minus the construction sector water withdrawal to obtain tertiary industry sectors water withdrawal of each province. Assuming that water intensities of each province's tertiary industry sectors are the same level as the provincial average level.

Compared with agricultural and industrial sectors, water intensities of construction and tertiary industry sectors are relatively stable. Therefore, the errors of assumptions are within a reasonable limitation. The quantity of water for public service of each province was collected from "China Urban-Rural Construction Statistic Yearbook 2012" (Ministry of Housing and Urban-Rural Development, 2013). The quantity of water usage data and the quantity of total available water of each province were obtained from "China Statistical Yearbook 2013" (National Bureau of Statistics of China, 2013). The above treatment methods used to obtain sectorial water withdrawal of each province in China referred to literatures(Dong, et al., 2014, Jin, et al., 2017, Liang, et al., 2014).

\section{Results}

\subsection{Water footprint and virtual water flows driven by energy consumption in} China

Fig.1 shows water footprints of 30 provinces in China. Since the water usage data used in this paper is water withdrawal and its quantity in power sector is much higher than other energy sectors, therefore, power sector is presented separately. The water footprint caused by energy consumption refers to the total water consumption in a region caused by final demand for energy, including direct water usage to supply local energy demand and all the indirect water usage to supply foreign energy demand. Among water footprints of all provinces(Fig.1(A)), Xinjiang has the highest water footprint $\left(9.86 \times 10^{4} \mathrm{~m}^{3}\right)$, followed by Shandong, Shanxi, Hunan. In Xinjiang's water footprint, more than $70 \%$ is external water footprint, the large quantity of local water 
resources consumed to supply the external energy needs. Xinjiang, as Chinese major energy base, has rich petroleum and coal resources, however Xinjiang is located in the arid northwest of China where water scarcity is severe. Consequently, the high water footprint caused by energy consumption make their water environment even worse. As a major coal resources province in China, Shanxi is an important energy and industrial base. Its coal production supplies the whole country, resulting in external water footprint of $70 \%$ of total water footprint. In China's total energy consumption water footprint, the electricity and hot water production and supply sectors account for $91 \%$. China's electricity consumption has quadrupled in the past decade, with more than $80 \%$ supplied by thermal power plants. Water withdrawal varies significantly due to the different cooling systems used in thermal power plants. In southern and coastal areas of China, where water resources are more abundant than in northern areas, power plants often use open-loop cooling technology, which requires a large amount of water to achieve cooling effect. In Fig.1(B), among power sector's water footprints of all provinces, Jiangsu has the highest energy consumption water footprint $\left(1.95 \times 10^{6} \mathrm{~m}^{3}\right)$, followed by Jiangxi, Shanghai and Yunnan. In Jiangsu's water footprint, $43 \%$ is external water footprint, which means more than half of water footprint is consumed by local energy demand, namely internal water footprint. 
(A) 12

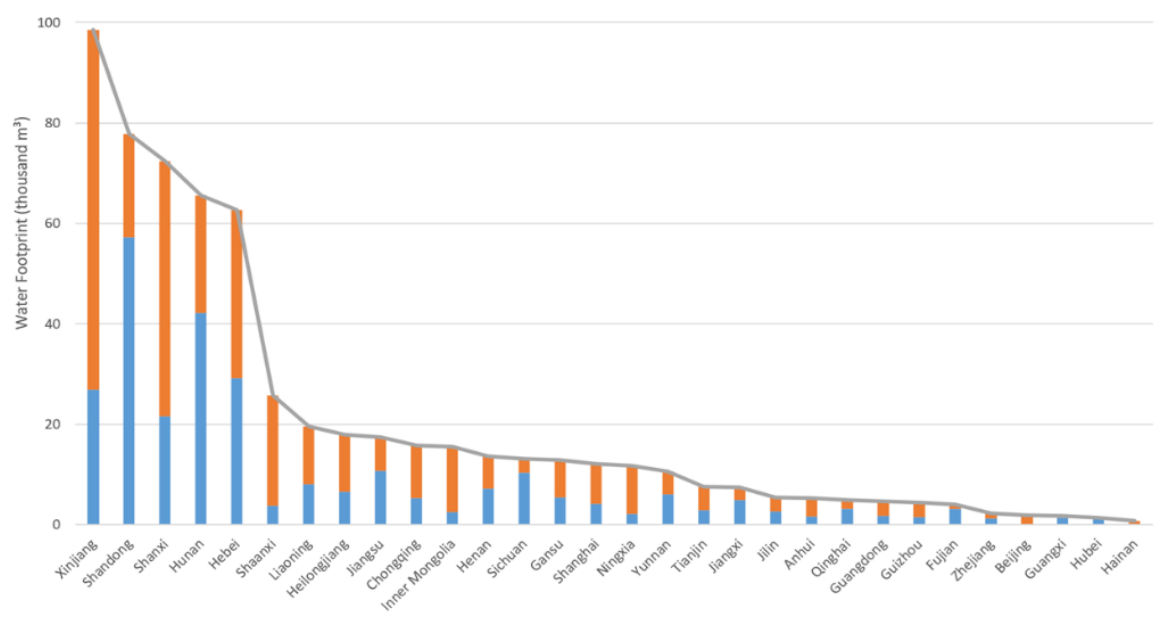

(B)

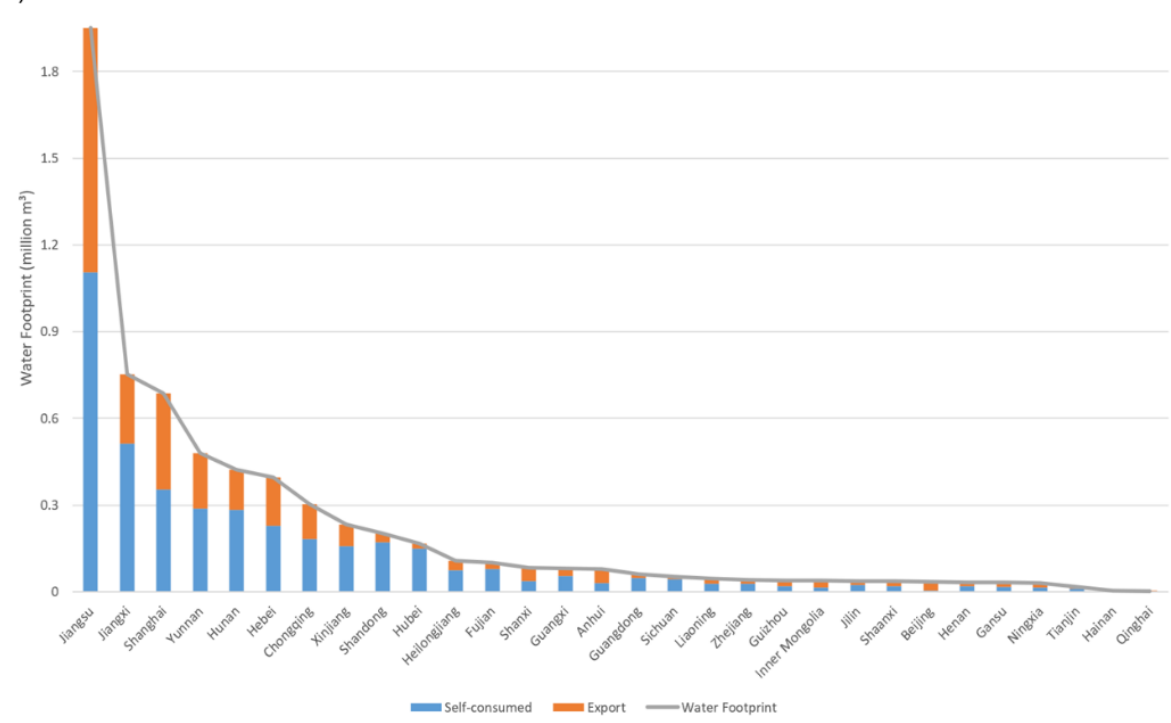

Fig. 1. Energy consumption-based water footprint for 30 Chinese provinces (Energy sectors showed in figure(A): Coal mining (No. 2), Petroleum and gas (No. 3), Petroleum refining, coking, etc. (No. 11). Energy sector showed in figure(B): Electricity and hot water production and supply (No. 22)) 

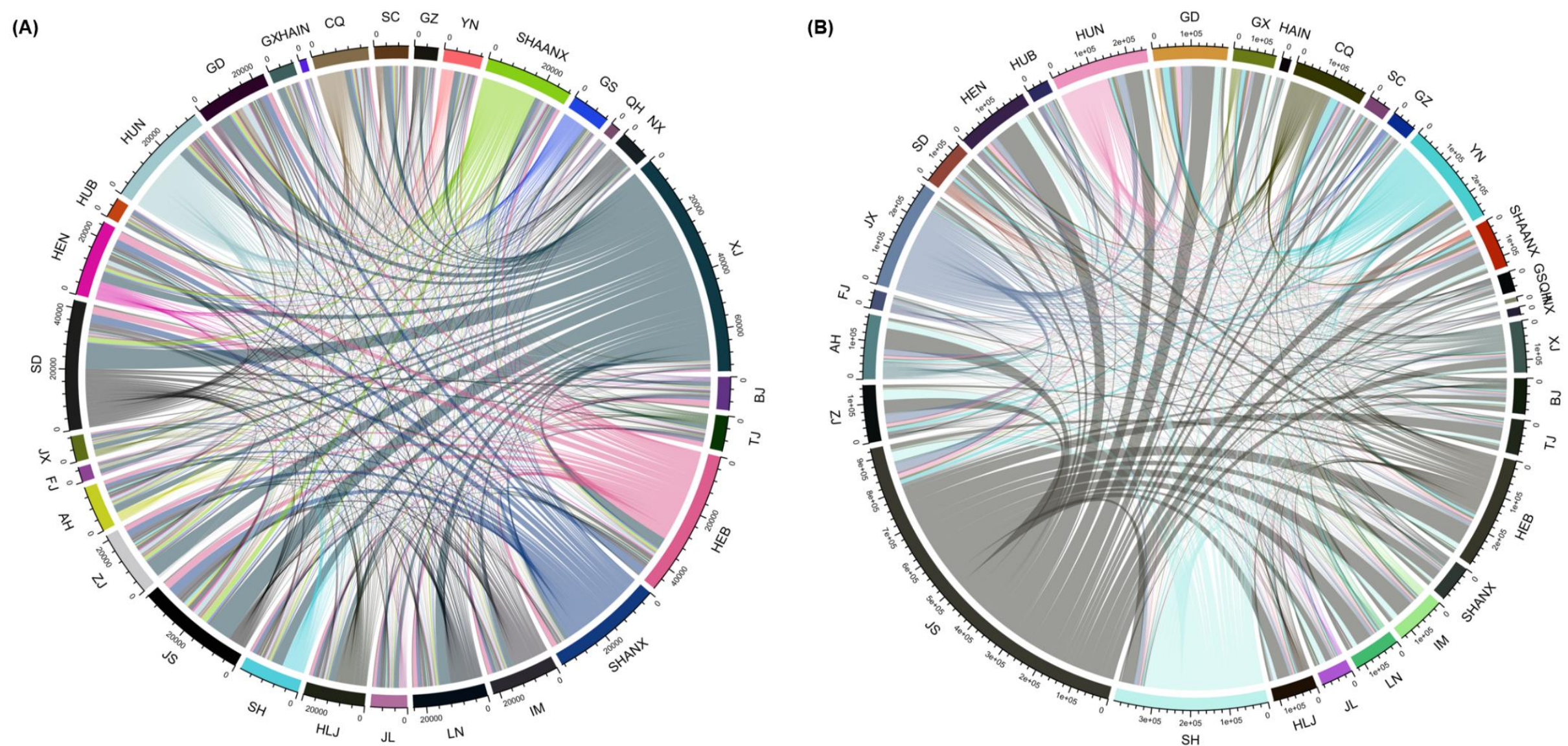

Fig. 2. Energy consumption-based virtual water flows for 30 provinces in China. Energy sectors showed in figure(A): Coal mining (No. 2), Petroleum and gas (No. 3), Petroleum refining, coking, etc. (No. 11). Energy sector showed in figure(B): Electricity and hot water production and supply (No. 22). Meanings for provinces abbreviations are listed in Table A1. 
The national water footprint caused by energy consumption is $6.87 \times 10^{6} \mathrm{~m}^{3}$, of which virtual water flows caused by inter-regional energy trade account for $40 \%$. Because the distribution of energy and water resources in China has significant regional differences, as a result, energy trade between provinces is closely linked. More than four out of ten energy consumption-based national water footprint is virtual water flows. In the rankings of 30 provinces' virtual water export, virtual water exports of the provinces in north and northwest of China are significantly higher than that of provinces in southern areas.

Fig. 2 shows whereabouts and sources of energy consumption-based virtual water flows in China. From fig. 2(A), Xinjiang has the highest virtual water export flow volume $\left(0.07 \times 10^{6} \mathrm{~m}^{3}\right)$, followed by Hebei $\left(0.03 \times 10^{6} \mathrm{~m}^{3}\right)$ and Shanxi $(0.03 \times$ $10^{6} \mathrm{~m}^{3}$ ). Xinjiang's virtual water exports account for $73 \%$ of its total water footprint, among the provinces that import virtual water from Xinjiang, Shandong accounts for the largest share (12\%), followed by Jiangsu (12\%) and Zhejiang (8\%). In the provinces that import virtual water from Shanxi, Jiangsu accounts for the largest share (11\%), followed by Hebei (10\%) and Shandong (9\%). Hebei's virtual water exports account for $53 \%$ of its total water footprint, amid provinces that import virtual water from Hebei, Henan accounts for the largest share (9\%), followed by Jiangsu (8\%), Shandong (8\%) and Beijing (7\%). Due to the specific characteristics of energy trade structure in China, water-scarce regions export large amounts of virtual water to regions with relatively low water stress. In the inter-provincial virtual water transfer network caused by energy consumption of three energy sectors (Coal mining, Petroleum and gas, Petroleum refining, coking, etc.), virtual water import provinces are principally located at coastal and southern areas. Amongst virtual water imports of all provinces(Fig. 2(A)), Jiangsu has the highest virtual water import flow volume $\left(0.03 \times 10^{6} \mathrm{~m}^{3}\right)$, followed by Shandong $\left(0.02 \times 10^{6} \mathrm{~m}^{3}\right)$ and Guangdong $(0.02 \times$ $\left.10^{6} \mathrm{~m}^{3}\right)$. In the provinces that export virtual water to Jiangsu, Xinjiang accounts for the largest proportion (27\%), followed by Shanxi (12\%) and Hebei (9\%). Among the provinces that export virtual water to Shandong, Xinjiang has the largest share (38\%), followed by Shanxi (13\%) and Hebei (12\%). Of which the provinces that export virtual water to Guangdong, Xinjiang has the largest share (18\%), followed by Hunan $(11 \%)$ and Shanxi (10\%).

Fig.2(B) shows whereabouts and sources of virtual water flows of 30 provinces caused by power sector's consumption in China. In northern and northwestern areas 
of China, due to shortage of water resources, power plants mostly use closed-loop cooling or air-cooling technology, compared with power plants in southern and coastal areas, where mostly using open-loop cooling technology, water withdrawals in north are significantly lower than that in south. Jiangsu has the highest virtual water export quantity $\left(0.81 \times 10^{6} \mathrm{~m}^{3}\right)$, followed by Shanghai $\left(0.33 \times 10^{6} \mathrm{~m}^{3}\right)$, Jiangxi $\left(0.24 \times 10^{6} \mathrm{~m}^{3}\right)$. In the provinces that import virtual water from Jiangsu, Henan accounts for the largest share (9\%), followed by Guangdong (8\%) and Anhui (7\%). In the provinces that import virtual water from Jiangxi, Jiangsu (9\%) accounts for the largest proportion, followed by Guangdong (9\%), Zhejiang (9\%) and Hunan (9\%). In virtual water export flows, which are caused by electricity consumption, the Yangtze River Delta area ranks first in virtual water export provinces, where exports virtual water mostly to southern provinces.

\subsection{Local water scarcity risks for Chinese provinces}

Due to the differences of water shortage in different regions, the effect of water extraction with the same quantity on water-rich regions and water-deficient regions will be significantly different. In order to reveal the impact of water scarcity on energy systems in different regions, this paper conducts a quantitative analysis of this impact, studies the impact of water scarcity on local energy systems in regions with different water stresses, as well as the transfer paths of virtual water scarcity risks caused by energy consumption.

Fig. 3 shows local water scarcity risks of 30 provinces in China. Xinjiang has the highest local water scarcity risk, followed by Shandong, Hebei and Shanxi. In the ranking of local water scarcity risks, top provinces are the provinces with extremely high water stresses. In Xinjiang's local water scarcity risk, the loss risk of petroleum and gas sector accounts for the largest proportion. In Shanxi's local water scarcity risk, the risk of coal mining sector production has the largest share. In local water scarcity risks of all provinces, the proportion caused by Electricity and hot water production and supply sector is much higher than that of other energy sectors. In Fig. 3(B), Jiangsu has the biggest risk, followed by Hebei and Xinjiang. Due to the climate differences, China has an arid north and a humid south, power plants in north mostly use closed-loop cooling, while power plants in south, especially in coastal areas, mostly use open-loop cooling, which explains why coastal provinces have the highest local water scarcity risks caused by electricity production.

The ratio of virtual water scarcity risk export to the total water scarcity risk of each 
province is calculated, as shown in Fig. 4(A). Inner Mongolia topped the list (73\%), followed by Shaanxi (68\%) and Shanxi (63\%). Provinces with more than half proportion of virtual water scarcity risk exports are concentrated in north and northwest. When water scarcity problems deepening, the virtual water scarcity risk in these provinces will be exported to other regions, posing a threat to the energy stability of other provinces. Fig.4(B) shows the proportions of virtual water scarcity risk imported by each province in their total water scarcity risk. Qinghai topped the list (100\%), followed by Hainan (99\%) and Zhejiang (99\%). The ratio of virtual water scarcity risk imported by Qinghai to its total water scarcity risk is $100 \%$. Since the water stress index of Qinghai is less than 0.05, the water deprivation risk of Qinghai is treated as 0 . Therefore, the water scarcity risk of this region is all imported from other provinces. In China, more than three-quarters of provinces have larger than $50 \%$ of virtual water scarcity risk imports. These provinces rely heavily on imports for their energy consumption and their high dependence on energy supplies from other provinces makes them more sensitive and vulnerable to other provinces' water scarcity problems. When other provinces face serious water scarcity problems that affect local energy system, these provinces will bear a large amount of virtual water scarcity risks from those provinces. 
(A)

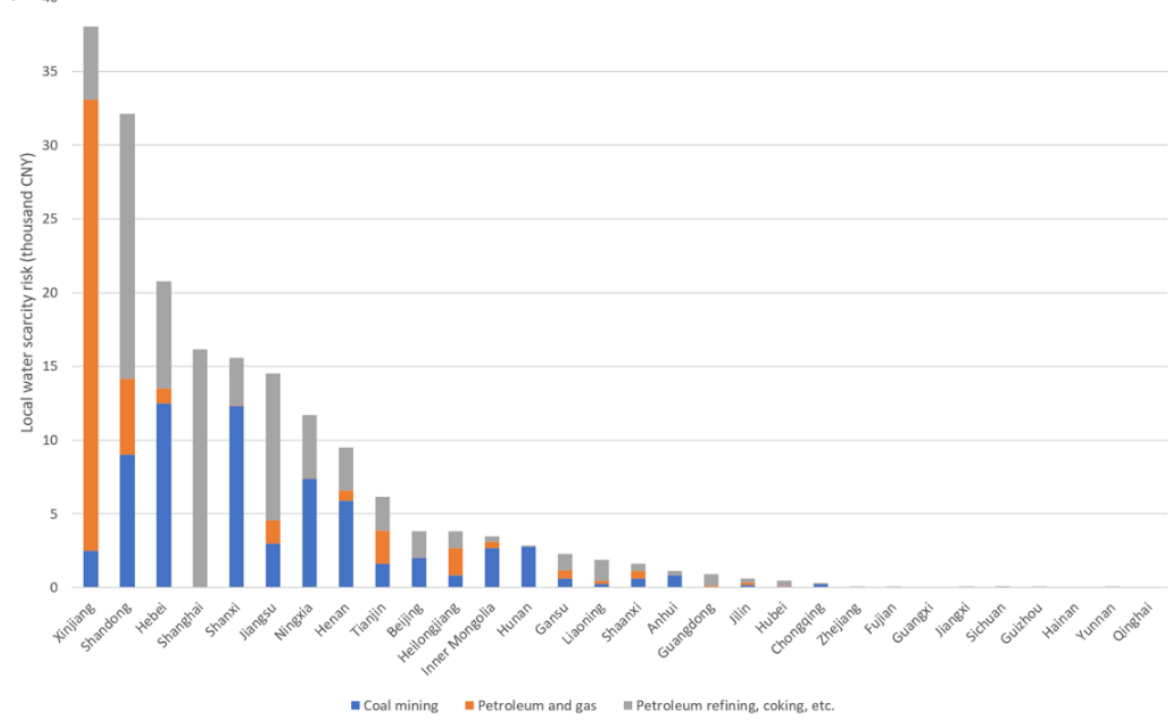

(B)

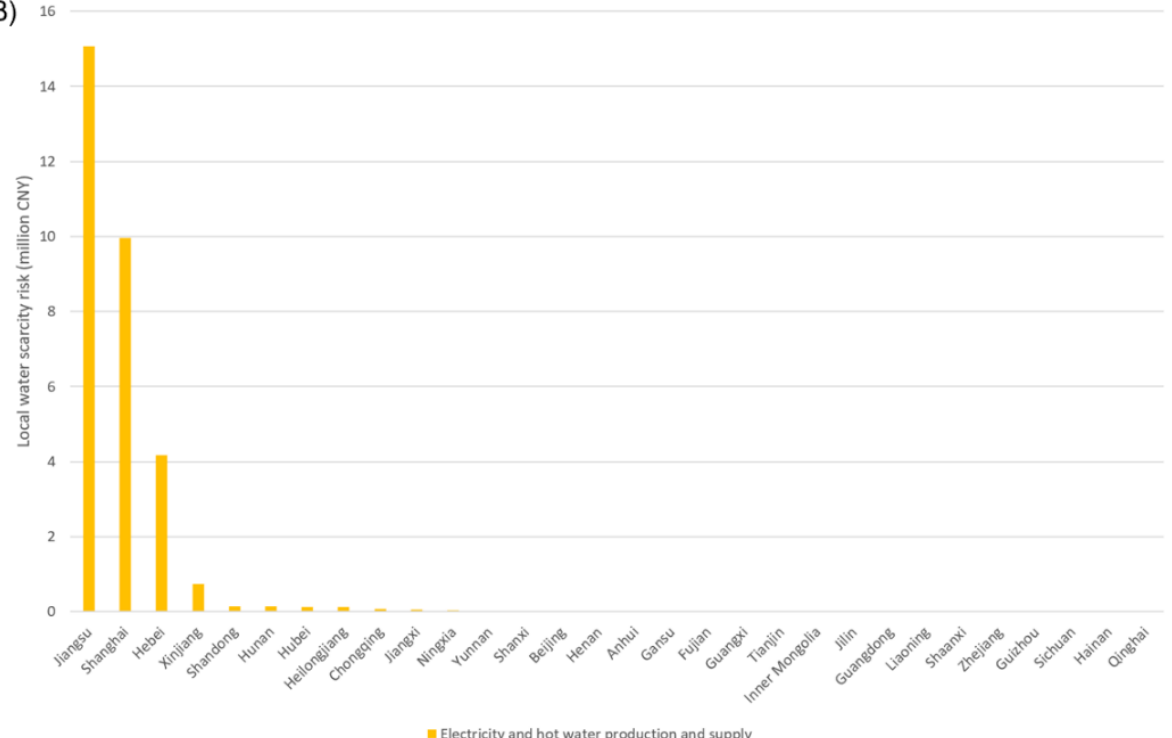

Fig. 3. Local water scarcity risks for 30 provinces in China (Energy sectors showed in figure(A): Coal mining (No. 2), Petroleum and gas (No. 3), Petroleum refining, coking, etc. (No. 11). Energy sector showed in figure(B): Electricity and hot water production and supply (No. 22)) 

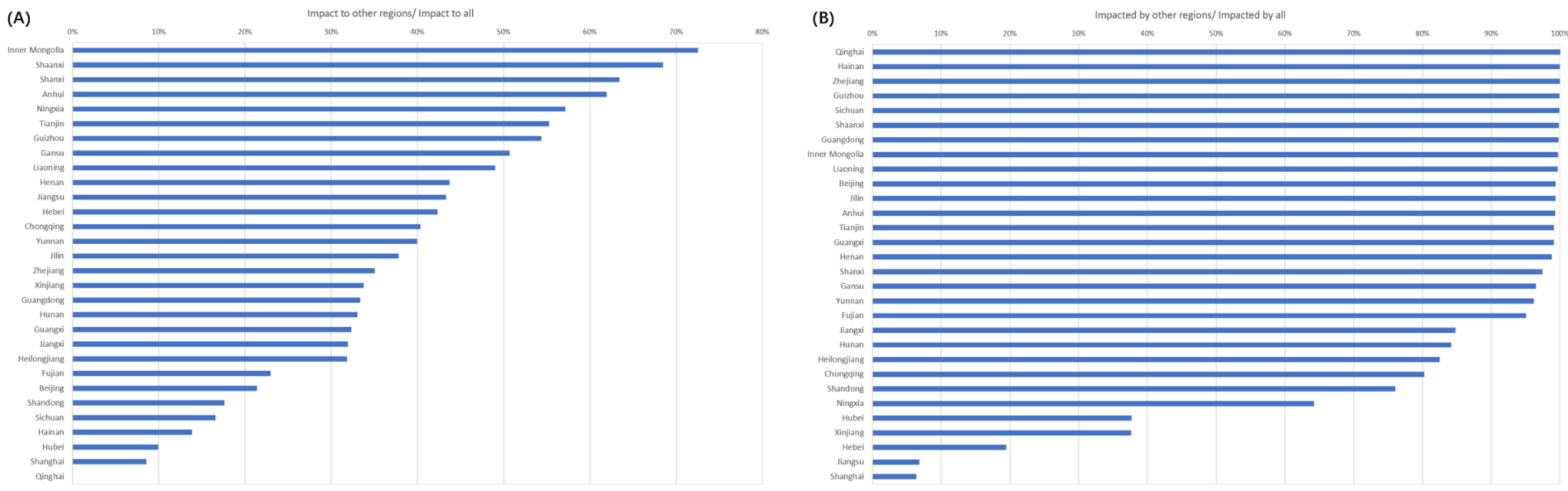

Fig. 4. Share of each province's virtual water scarcity risk export (A) and import (B) in total exerted and received risks. 


\subsection{Virtual water scarcity risk transfers caused by energy consumption in}

\section{China}

In virtual water scarcity risk exporting provinces, those with high share of virtual water scarcity risk exports are mostly in north and northwest of China. Due to their geographical location and climate, which makes these provinces more likely to face severe water scarcity problems, while energy resources are concentratedly located in these provinces, virtual water scarcity risks caused by energy consumption will be passed on to other areas as energy exports. Fig. 5(A) shows the main virtual water scarcity risk exporting provinces and the destinations of their exporting flows. In the provinces that importing virtual water scarcity risks from Xinjiang, Shandong (9\%) accounts for the largest proportion, followed by Hebei (8\%), Jiangsu (8\%) and Zhejiang $(6 \%)$. Among the provinces where importing virtual water scarcity risks from Shanxi, Hebei (12\%) accounts for the largest proportion, followed by Shandong (11\%), Jiangsu (9\%), Henan (7\%) and Zhejiang (6\%). And among the provinces where importing virtual water scarcity risks from Jiangsu, Henan (9\%) accounts for the largest proportion, followed by Guangdong (8\%), Anhui (7\%) and Hunan (6\%). In order to exclude the impact of the scale of economic output, the virtual water scarcity risk exports of unitary output of each province is calculated, namely the inter-regional trade risk index, dividing the virtual water scarcity risk export by the economic output. From Fig. 5(A), Jiangsu has the highest inter-regional trade risk index, followed by Hebei, Xinjiang and Chongqing. The virtual water scarcity risks of these provinces will be exported to other provinces through energy trading, which will affect the stability and security of national energy system. Therefore, these provinces play a significant role in the supply chain of national energy system.

Fig. 5(B) shows the major virtual water scarcity risk importing provinces and the sources of their importing flows. The importing sources of virtual water scarcity risks caused by power consumption are mainly from the Jing-Jin-Ji region and the Yangtze River Delta. The virtual water scarcity risks caused by coal and oil consumption are mainly from the north and northwest regions. Of which provinces that exporting virtual water scarcity risks to Shandong, Xinjiang (45\%) has the largest share, followed by Shanxi (14\%), Hebei (12\%) and Ningxia (7\%). In the provinces where exporting virtual water scarcity risks to Henan, Xinjiang $(21 \%)$ has the largest share, followed by Hebei (18\%), Shanxi (16\%) and Shandong (12\%). Among the provinces where exporting virtual water scarcity risks to Guangdong, Xinjiang (25\%) has the 
largest share, followed by Ningxia (15\%), Shanxi (14\%) and Hebei (9\%). In order to avoid the impact of different scales of economic output, the inter-regional trade vulnerability index is calculated, by dividing the virtual water scarcity risk import by the economic output. From Fig. 5(B), Guangxi has the highest inter-regional trade vulnerability index, followed by Anhui, Yunnan, Hunan and Chongqing. The virtual water scarcity risks are imported by these provinces through energy trading. Due to excessive dependency on energy imports, these provinces are highly vulnerable to the volatility of national energy system. When other provinces on the energy supply chain are facing worsening water scarcity problems, the virtual water scarcity risks will be spread through the energy supply chain to the importing provinces.

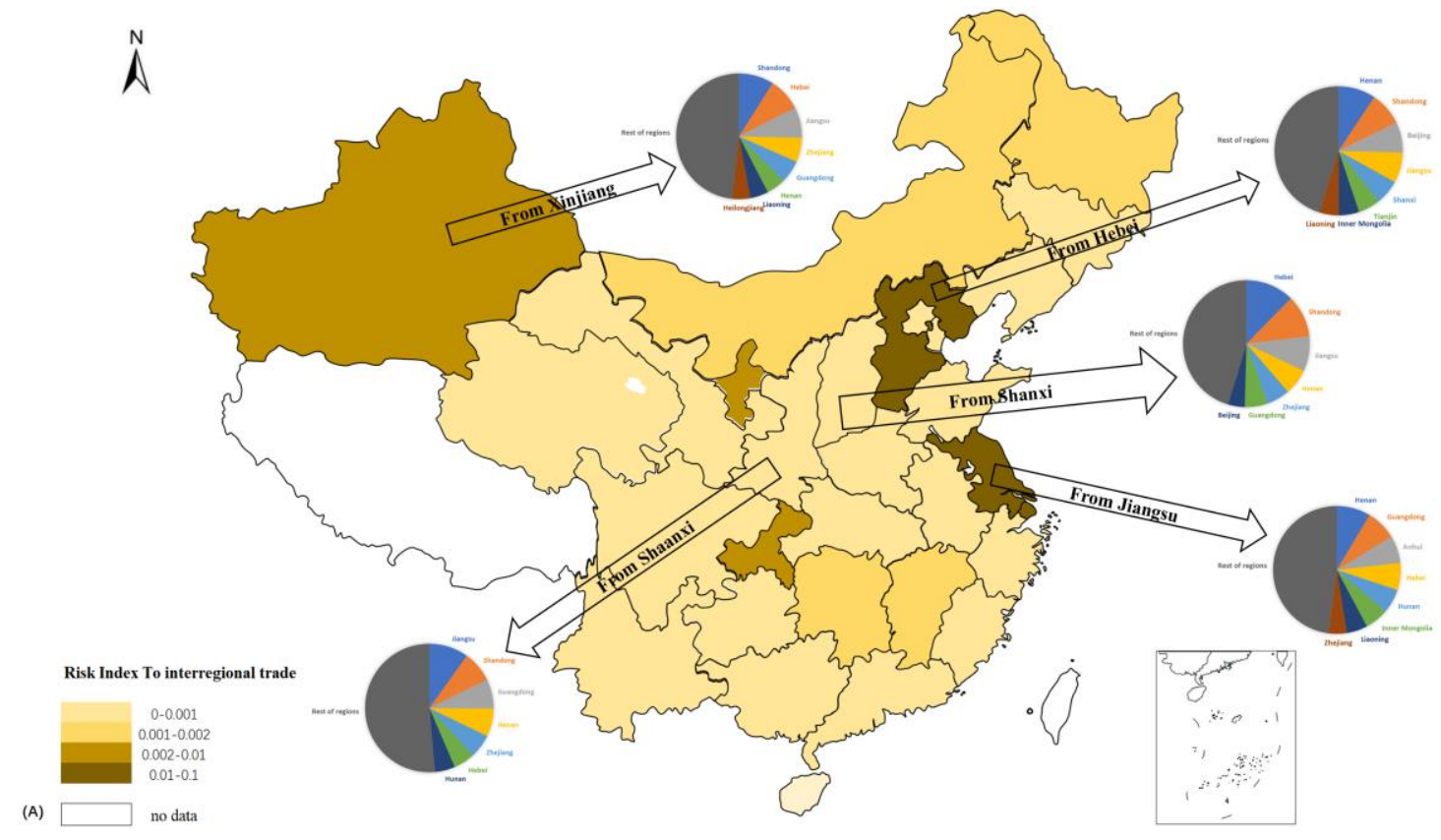




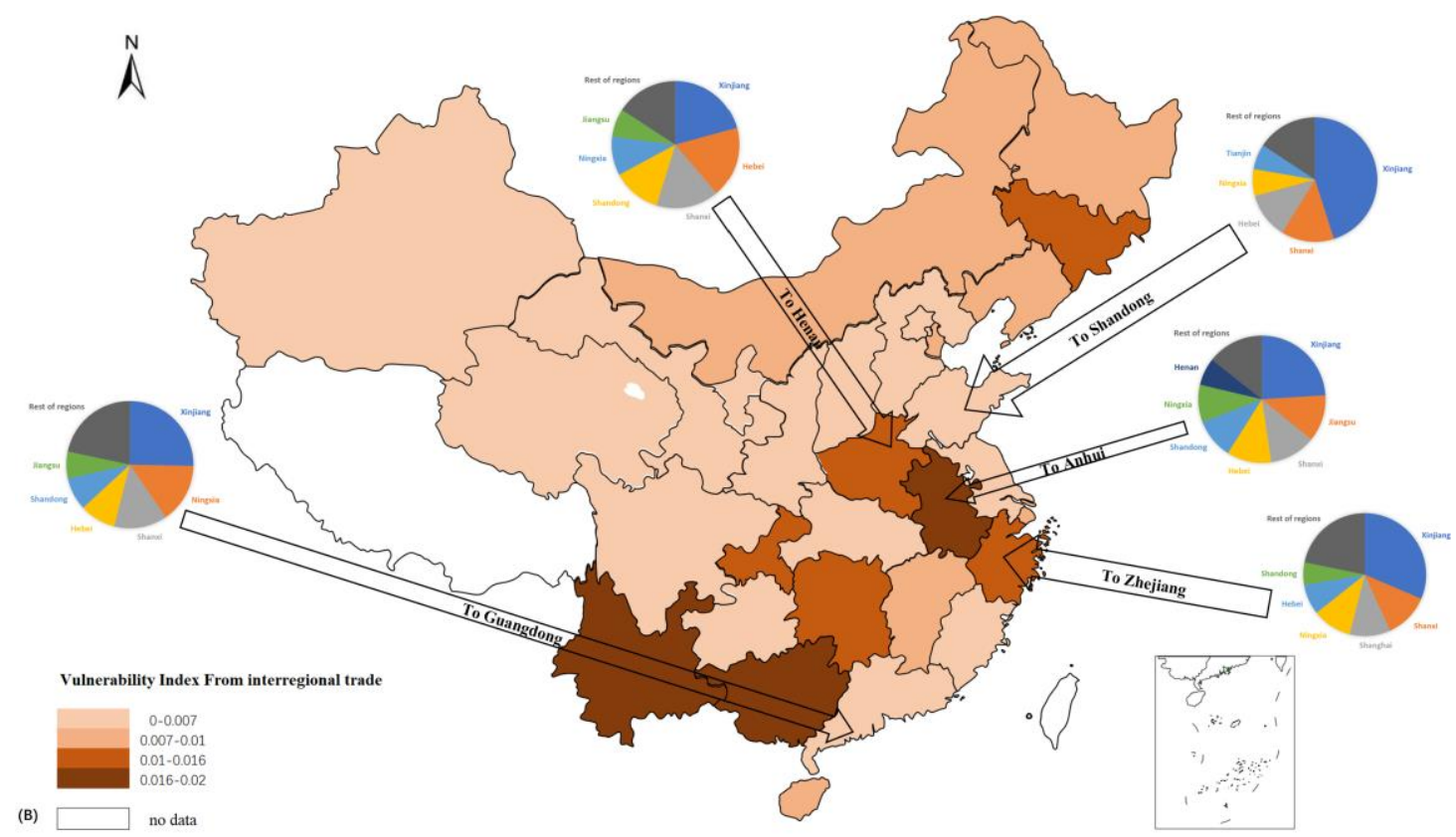

Fig. 5. Virtual water scarcity risk exports (A) and imports (B) by major provinces. Arrow width is set in proportion to measures of loss. Risk indices (A) are virtual water scarcity risk exports normalized by the total output of respective provinces, Vulnerability indices (B) are virtual water scarcity risk imports normalized by the total output of respective provinces.

\subsection{Sensitivity analysis}

By analyzing the provincial ranking of virtual water scarcity risk exports and imports caused by energy consumption, this paper identified key provinces in virtual water scarcity risk transfer network of China. The focus of this paper is the relative values and the ranking of virtual water scarcity risks of all provinces. The Kendall correlation coefficient is used to conduct a robustness study on the results of the provincial rankings. The water scarcity risk model is repeatedly calculated by more than 100 pairs by changing the value of two parameters in the water scarcity risk model: the parameter $\sigma$ in water deprivation risk (WDR) which is limiting the heterogeneity in different regions; and the parameter $\alpha$ in water dependence (WD) which is controlling the saturation value of water intensity. By recording the provincial ranking results of each parameter pair and comparing them with the benchmark case, the results of Kendall correlation coefficient are obtained (Fig. 6). When the Kendall correlation coefficient is close to 1 , it means that the provincial ranking result remains basically unchanged compared with the benchmark case. In terms of provincial ranking of water scarcity risk, the robustness of local water scarcity risk (LWSR) and virtual water scarcity risk (VWSR) exports are better than 
the robustness of virtual water scarcity risk imports. When changing the value of parameter pairs, each province's WDR and WD will change accordingly. When considering the ranking results of provincial water scarcity risks, LWSR and VWSR exports can contribute a greater reference value.
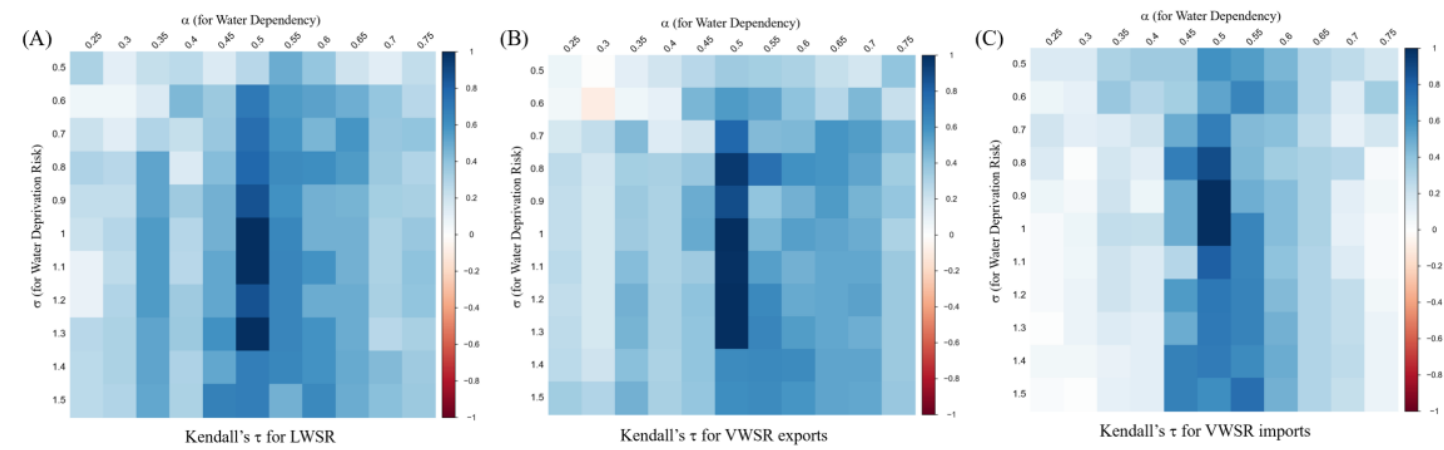

Fig. 6. Kendall rank correlation coefficients of rankings computed using different parameter values with the result presented in the main text (for which $\sigma=1$ and $\alpha=0.5$ ). The figures are for provincial LWSR (A), VWSR exports (B) and imports (C) respectively. Bluer areas indicate higher correlations and robustness.

\section{Discussion}

In China, the primary energy resources and electricity bases are mostly located in the north and northwest areas. In order to meet the increasing energy demand, these water-scarce areas have to further expand the production and supply of energy, resulting in deeply worsening local water scarcity problems. From the results of energy consumption-based water footprints, it indicates that there is a contradiction between water demand and water supply. This contradiction is constrained to large extent by the imbalance of regional economic development. In order to address this imbalance, Chinese government launched a few of national development strategies to vigorously promote the economic development of western, central and northeastern regions, making highly intensive industries such as chemical industries and power sectors transferred from coastal areas to inland areas (Cai, et al., 2019). To meet the growing energy demand, government plans to build several large-scale power bases in Xinjiang, Ningxia, Shanxi, etc. and invest in construction of inland nuclear power plants (Qin, et al., 2015, Shang, et al., 2017). The implementation of these policies is indeed conducive to promote economic development in western provinces and improve their local employment. It has shortened the distance between coal power bases and coal mines and greatly reduced the transportation cost of coal fuels, and played a positive role in controlling environmental pollution in coastal areas. But it 
allows a large amount of virtual water to be exported from water-scarce northwest regions to southeast regions. The current water consumption quantity of northwest provinces has already exceeded the available water quantity of ecological protection. The continuous virtual water exporting in water-scarce provinces will undoubtedly further aggravate local water scarcity (Shang, et al., 2016).

In the results of water scarcity risks, the underdeveloped northwest and northern areas have the highest local water scarcity risks and the highest virtual water scarcity risk exports. Due to the consumption of developed provinces, under-developed provinces would be fixed in water-intensive industries, so that arid provinces will have difficulty in maintaining harmonious development between economy and water resource protection (Jiang, et al., 2015, Wang, et al., 2020). The management of energy and water resources in China is carried out by two separate departments, resulting in the incompatibility of energy policies and water resources policies. This makes it impossible to manage and coordinate these two resources integrally. The mitigation policies for one resource may increase the pressure on the other resource. Whether energy policies should focus on supply-side management or demand-side is becoming the key point in decision-making process of government and relevant departments (Chini, et al., 2018).

The water withdrawal of power sector is the highest among all the energy sectors, the virtual water scarcity risk exports caused by power consumption are the highest. The main VWSR exporting provinces are in the Yangtze River Delta and the Huang-Huai-Hai region. In terms of power generation technology of thermal power plants, the coal-fired power plants in China have already adopted the most advanced world-class technology. In terms of cooling technologies, the water-rich regions have the tendency to use low efficiency technologies, thermal power plants can reduce the water withdrawal by optimizing their cooling systems, such as changing open-loop cooling to closed-loop cooling, and changing closed-loop cooling to air cooling. However, different cooling technologies will have different impact on power generation efficiency. For example, although air cooling technology has the lowest water withdrawal, it will reduce power generation efficiency and consume more coal fuels (Liao, et al., 2016). Therefore, for arid or semi-arid regions, before expanding the construction of energy bases, the impact on local water environment should be evaluated with consideration of the water scarcities. The scientific and sustainable management of water resources should be improved when balancing the relationship 
between energy and water (Lee, et al., 2019).

\section{Conclusion}

This paper identified the major VWSR exporters and importers by calculating and mapping the virtual water scarcity risk transfer network of energy system in China. In the energy consumption-based VWSR transfers, the VWSR importers, such as Henan, Anhui, Guangdong, will be the "victims" suffering the consequences of increasing virtual water scarcity risks in energy system. These provinces mainly import VWSR from Xinjiang, Shanxi and Shaanxi. For the major VWSR importers, they should focus on optimizing local energy consumption structure, such as improving energy efficiency and increasing investment in energy transition. By doing so these provinces could reduce local water scarcity risks meanwhile avoiding importing virtual water scarcity risks from upstream provinces in energy supply chain. For major VWSR exporters, they will transfer the virtual water scarcity risks into national energy system and spread the risks to downstream provinces along energy supply chain, threatening the stability of national energy supply system. Therefore, for these provinces, it is necessary to focus on the local energy and water relations. Before deploying energy strategic plans, it is of great necessity to evaluate the impact on water resources in the deployment areas. Although this paper uses China as an example to study the virtual water scarcity risk transfers in the energy system, this approach is also instructive for other countries facing the same problem and can be applied to other developing countries, such as the MENA region.

The limitations of calculation model and data used in this paper include the following two points: firstly, because the time point of the results is the year corresponding to the multi-regional input-output table, it is unlikely to capture the dynamic changes of inter-regional trade flows over time when the real water scarcity problems occur; secondly, because the divisions of MRIO table are relatively rough and cannot cover the trade flows of similar products within the sector, therefore, for provinces with different water scarcity problems, the results of virtual water scarcity risks caused by similar products consumption may vary differently. Future research could use high-resolution sub-divided categories to further improve the accuracy of water scarcity risk assessment.

\section{Acknowledgements}

The authors appreciate the China Scholarship Council (201906440186) for sponsoring this research. 


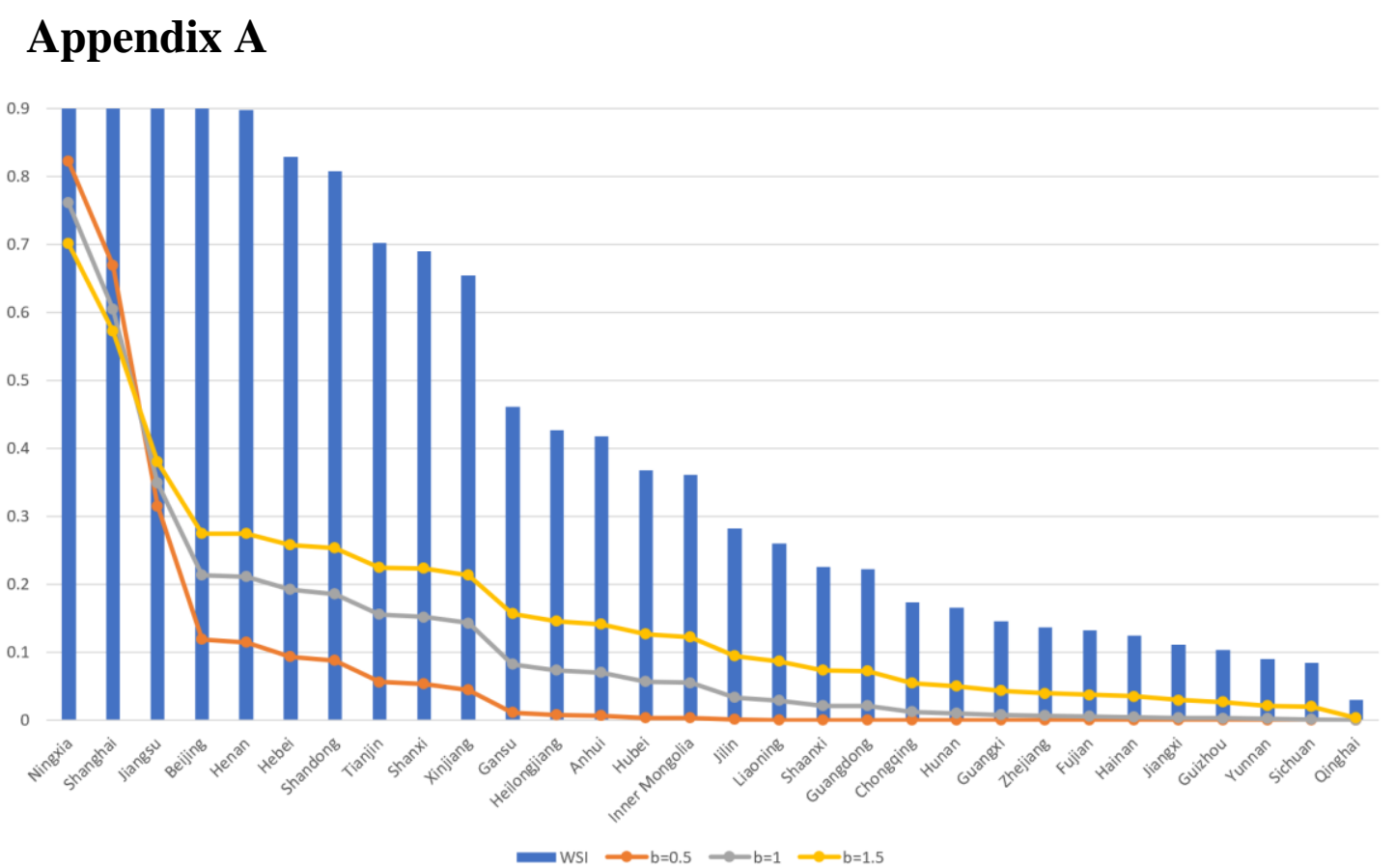

Fig. A1. Water stress index (WSI) and the resulting water deprivation risk (WDR) at different value of parameter $\sigma$.

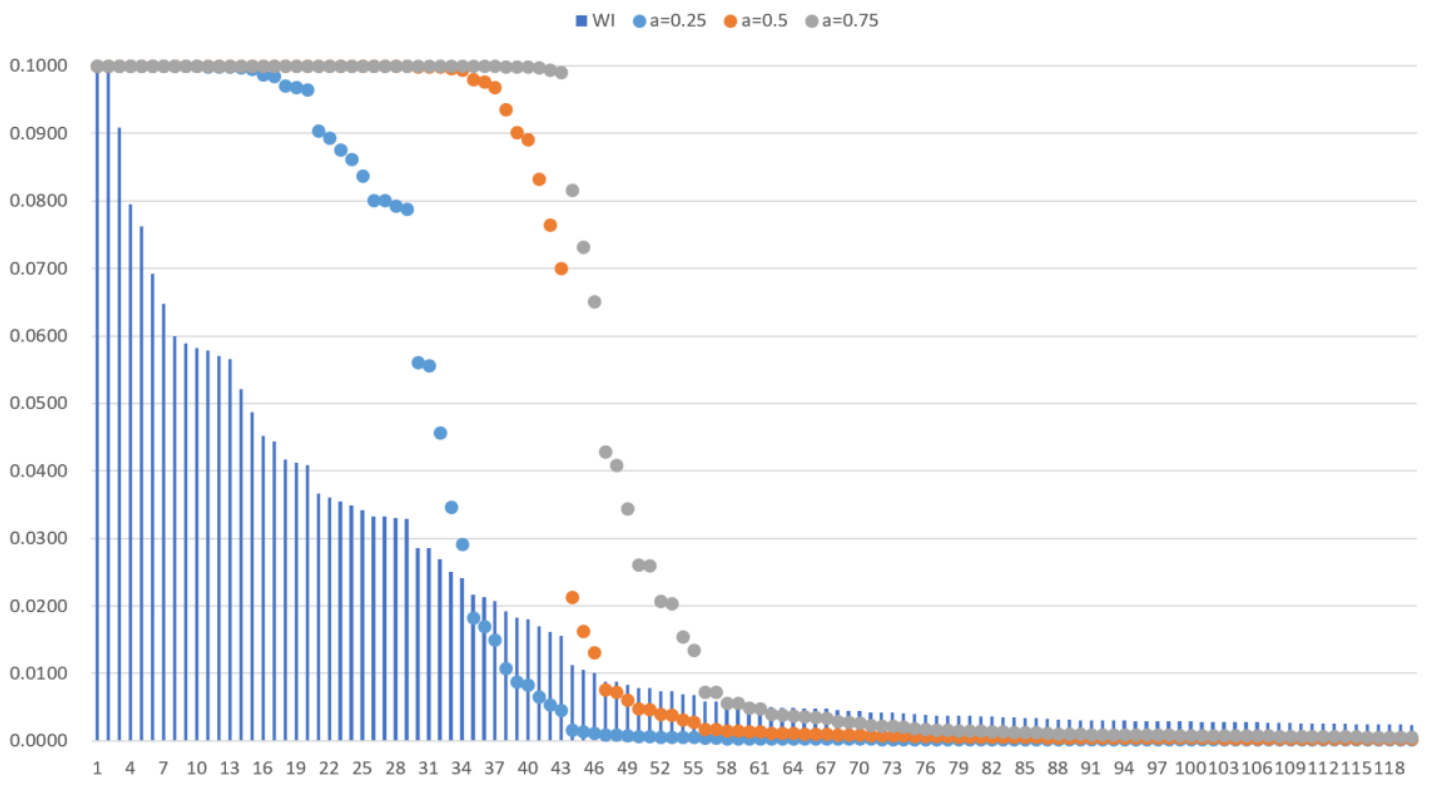

Fig. A2. Water intensity (WI) and the inferred water dependency of sectors in all provinces of China. Only sectors with water intensity $>0.002 \mathrm{~m}^{3} / \mathrm{CNY}$ are shown.

Table A1. Provinces abbreviations

Number Full name of province Abbreviation




\begin{tabular}{|c|c|}
\hline Beljing & $\mathrm{BJ}$ \\
\hline Tianjin & $\mathrm{TJ}$ \\
\hline Hebei & HEB \\
\hline Shanxi & SHANX \\
\hline Inner Mongolia & $\mathrm{IM}$ \\
\hline Liaoning & LN \\
\hline Jilin & $\mathrm{JL}$ \\
\hline Heilongjiang & HLJ \\
\hline Shanghai & $\mathrm{SH}$ \\
\hline Jiangsu & JS \\
\hline Zhejiang & $\mathrm{ZJ}$ \\
\hline Anhui & $\mathrm{AH}$ \\
\hline Fujian & FJ \\
\hline Jiangxi & JX \\
\hline Shandong & $\mathrm{SD}$ \\
\hline Henan & HEN \\
\hline Hubei & HUB \\
\hline Hunan & HUN \\
\hline Guangdong & GD \\
\hline Guangxi & GX \\
\hline Hainan & HAIN \\
\hline Chongqing & CQ \\
\hline Sichuan & $\mathrm{SC}$ \\
\hline Guizhou & GZ \\
\hline Yunnan & YN \\
\hline Shaanxi & SHAANX \\
\hline Gansu & GS \\
\hline Qinghai & $\mathrm{QH}$ \\
\hline Ningxia & NX \\
\hline Xinjiang & $\mathrm{XJ}$ \\
\hline
\end{tabular}

\section{Table A2. Sectors classification}

\begin{tabular}{ll}
\hline Number & Full name of sector \\
\hline 1 & Agriculture \\
2 & Coal mining \\
3 & Petroleum and gas \\
4 & Metal mining \\
5 & Nonmetal mining \\
6 & Food processing and tobaccos \\
7 & Textile \\
8 & Clothing, leather, fur, etc. \\
9 & Wood processing and furnishing
\end{tabular}




\begin{tabular}{ll}
10 & Paper making, printing, stationery, etc. \\
11 & Petroleum refining, coking, etc. \\
12 & Chemical industry \\
13 & Nonmetal products \\
14 & Metallurgy \\
15 & Metal products \\
16 & General and specialist machinery \\
17 & Transport equipment \\
18 & Electrical equipment \\
19 & Electronic equipment \\
20 & Instrument and meter \\
21 & Other manufacturing \\
22 & Electricity and hot water production and supply \\
23 & Gas and water production and supply \\
24 & Construction \\
25 & Transport and storage \\
26 & Wholesale and retailing \\
27 & Hotel and restaurant \\
28 & Leasing and commercial services \\
29 & Scientific research \\
30 & Other services \\
\hline &
\end{tabular}

\section{References}

[1] Lee, U., Xu, H., Daystar, J., Elgowainy, A., Wang, M. AWARE-US: Quantifying water stress impacts of energy systems in the United States. Science of The Total Environment. 2019,648:1313-1322.

[2] Distefano, T., Kelly, S. Are we in deep water? Water scarcity and its limits to economic growth. Ecological Economics. 2017,142:130-147.

[3] Cai, J., Varis, O., Yin, H. China's water resources vulnerability: A spatio-temporal analysis during 2003-2013. Journal of Cleaner Production. 2017,142:2901-2910.

[4] Fan, J.-L., Kong, L.-S., Zhang, X., Wang, J.-D. Energy-water nexus embodied in the supply chain of China: Direct and indirect perspectives. Energy Conversion and Management. 2019,183:126-136.

[5] Zhao, X., Liu, J., Liu, Q., Tillotson, M.R., Guan, D., Hubacek, K. Physical and virtual water transfers for regional water stress alleviation in China. Proc Natl Acad Sci U S A. 2015,112(4):1031-5.

[6] Sun, L., Pan, B., Gu, A., Lu, H., Wang, W. Energy-water nexus analysis in the BeijingTianjin-Hebei region: Case of electricity sector. Renewable and Sustainable Energy Reviews. 2018,93:27-34.

[7] Allan, J.A. Virtual Water A Strategic Resource Global Solutions to Regional Deficits. Groundwater. 1998,36:545-546.

[8] Liu, J., Yang, W. Water management. Water sustainability for China and beyond. Science. 
2012,337(6095):649-50.

[9] Zhang, C., Anadon, L.D. A multi-regional input-output analysis of domestic virtual water trade and provincial water footprint in China. Ecological Economics. 2014,100:159-172.

[10] Chen, W., Wu, S., Lei, Y., Li, S. Virtual water export and import in china's foreign trade: A quantification using input-output tables of China from 2000 to 2012. Resources, Conservation and Recycling. 2018,132:278-290.

[11] Wang, S., Liu, Y., Chen, B. Multiregional input-output and ecological network analyses for regional energy-water nexus within China. Applied Energy. 2018,227:353-364.

[12] Zhang, S., Taiebat, M., Liu, Y., Qu, S., Liang, S., Xu, M. Regional water footprints and interregional virtual water transfers in China. Journal of Cleaner Production. 2019,228:1401-1412.

[13] Cai, B., Zhang, W., Hubacek, K., Feng, K., Li, Z., Liu, Y., Liu, Y. Drivers of virtual water flows on regional water scarcity in China. Journal of Cleaner Production. 2019,207:1112-1122.

[14] IEA, World Energy Outlook 2016[R], IEA, Paris, 2016.

[15] IEA, Global Energy \& CO2 Status Report 2019, IEA, Paris, 2019.

[16] IEA, Global Energy Review 2019, IEA, Paris, 2020.

[17] Shang, Y., Wang, J., Liu, J., Jiang, D., Zhai, J., Jiang, S. Suitability analysis of China's energy development strategy in the context of water resource management. Energy. 2016,96:286-293.

[18] Qin, Y., Curmi, E., Kopec, G.M., Allwood, J.M., Richards, K.S. China's energy-water nexus - assessment of the energy sector's compliance with the "3 Red Lines" industrial water policy. Energy Policy. 2015,82:131-143.

[19] Feng, C., Tang, X., Jin, Y., Höök, M. The role of energy-water nexus in water conservation at regional levels in China. Journal of Cleaner Production. 2019,210:298-308.

[20] Tang, X., Jin, Y., Feng, C., McLellan, B.C. Optimizing the energy and water conservation synergy in China: 2007-2012. Journal of Cleaner Production. 2018,175:8-17.

[21] Larsen, M.A.D., Drews, M. Water use in electricity generation for water-energy nexus analyses: The European case. Sci Total Environ. 2019,651(Pt 2):2044-2058.

[22] Bravo, H.R. Assessing the effects of thermal and hydro energy production on water systems. Journal of Environmental Studies and Sciences. 2016,6(1):140-148.

[23] Chini, C.M., Djehdian, L.A., Lubega, W.N., Stillwell, A.S. Virtual water transfers of the US electric grid. Nature Energy. 2018,3(12):1115-1123.

[24] Liao, X., Zhao, X., Jiang, Y., Liu, Y., Yi, Y., Tillotson, M.R. Water footprint of the energy sector in China's two megalopolises. Ecological Modelling. 2019,391:9-15.

[25] Liao, X., Hall, J.W., Eyre, N. Water use in China's thermoelectric power sector. Global Environmental Change. 2016,41:142-152.

[26] Leontief, W. Environmental repercussions and the economic structure: an input-output approach. The Review of Economics and Statistics. 1970,52:262-271.

[27] Dong, H., Geng, Y., Hao, D., Yu, Y., Chen, Y. Virtual water flow feature of water-rich province and the enlightenments: Case of Yunnan in China. Journal of Cleaner Production. 2019,235:328-336.

[28] Liao, X., Zhao, X., Hall, J.W., Guan, D. Categorising virtual water transfers through China's electric power sector. Applied Energy. 2018,226:252-260. 
[29] Zhang, C., Zhong, L., Liang, S., Sanders, K.T., Wang, J., Xu, M. Virtual scarce water embodied in inter-provincial electricity transmission in China. Applied Energy. 2017,187:438-448.

[30] Ridoutt, B.G., Hadjikakou, M., Nolan, M., Bryan, B.A. From Water-Use to Water-Scarcity Footprinting in Environmentally Extended Input-Output Analysis. Environ Sci Technol. 2018,52(12):6761-6770.

[31] Qu, S., Liang, S., Konar, M., Zhu, Z., Chiu, A.S.F., Jia, X., Xu, M. Virtual Water Scarcity Risk to the Global Trade System. Environ Sci Technol. 2018,52(2):673-683.

[32] Peters, G.P. From production-based to consumption-based national emission inventories. Ecological Economics. 2008,65(1):13-23.

[33] Mi, Z., Meng, J., Guan, D., Shan, Y., Song, M., Wei, Y.M., Liu, Z., Hubacek, K. Chinese CO2 emission flows have reversed since the global financial crisis. Nat Commun. 2017,8(1):1712.

[34] National Bureau of Statistics of China, China Statistical Yearbook 2013, China Statistics Press, Beijing, 2013.

[35] National Bureau of Statistics of China, China Economic Census Yearbook 2008, China Statistics Press, Beijing, 2010.

[36] Ministry of Water Resources, Bulletin of First National Census for Water, China Water Resource and Hydro-power Publishing House, Beijing, 2013.

[37] Ministry of Water Resources, China Water Bulletin 2012, China Water Resource and Hydro-power Publishing House, Beijing, 2013.

[38] Ministry of Housing and Urban-Rural Development, China Urban-rural Construction Statistic Yearbook 2012, China Statistics Press, Beijing, 2013.

[39] Dong, H., Geng, Y., Fujita, T., Fujii, M., Hao, D., Yu, X. Uncovering regional disparity of China's water footprint and inter-provincial virtual water flows. Sci Total Environ. 2014,500-501:120-30.

[40] Jin, Y., Tang, X., Feng, C., Höök, M. Energy and water conservation synergy in China: 2007-2012. Resources, Conservation and Recycling. 2017,127:206-215.

[41] Liang, S., Liu, Z., Crawford-Brown, D., Wang, Y., Xu, M. Decoupling analysis and socioeconomic drivers of environmental pressure in China. Environ Sci Technol. 2014,48(2):1103-13.

[42] Shang, Y., Lu, S., Li, X., Hei, P., Lei, X., Gong, J., Liu, J., Zhai, J., Wang, H. Balancing development of major coal bases with available water resources in China through 2020. Applied Energy. 2017,194:735-750.

[43] Jiang, Y., Cai, W., Du, P., Pan, W., Wang, C. Virtual water in interprovincial trade with implications for China's water policy. Journal of Cleaner Production. 2015,87:655-665.

[44] Wang, H., Wang, G., Qi, J., Schandl, H., Li, Y., Feng, C., Yang, X., Wang, Y., Wang, X., Liang, S. Scarcity-weighted fossil fuel footprint of China at the provincial level. Applied Energy. 2020,258. 


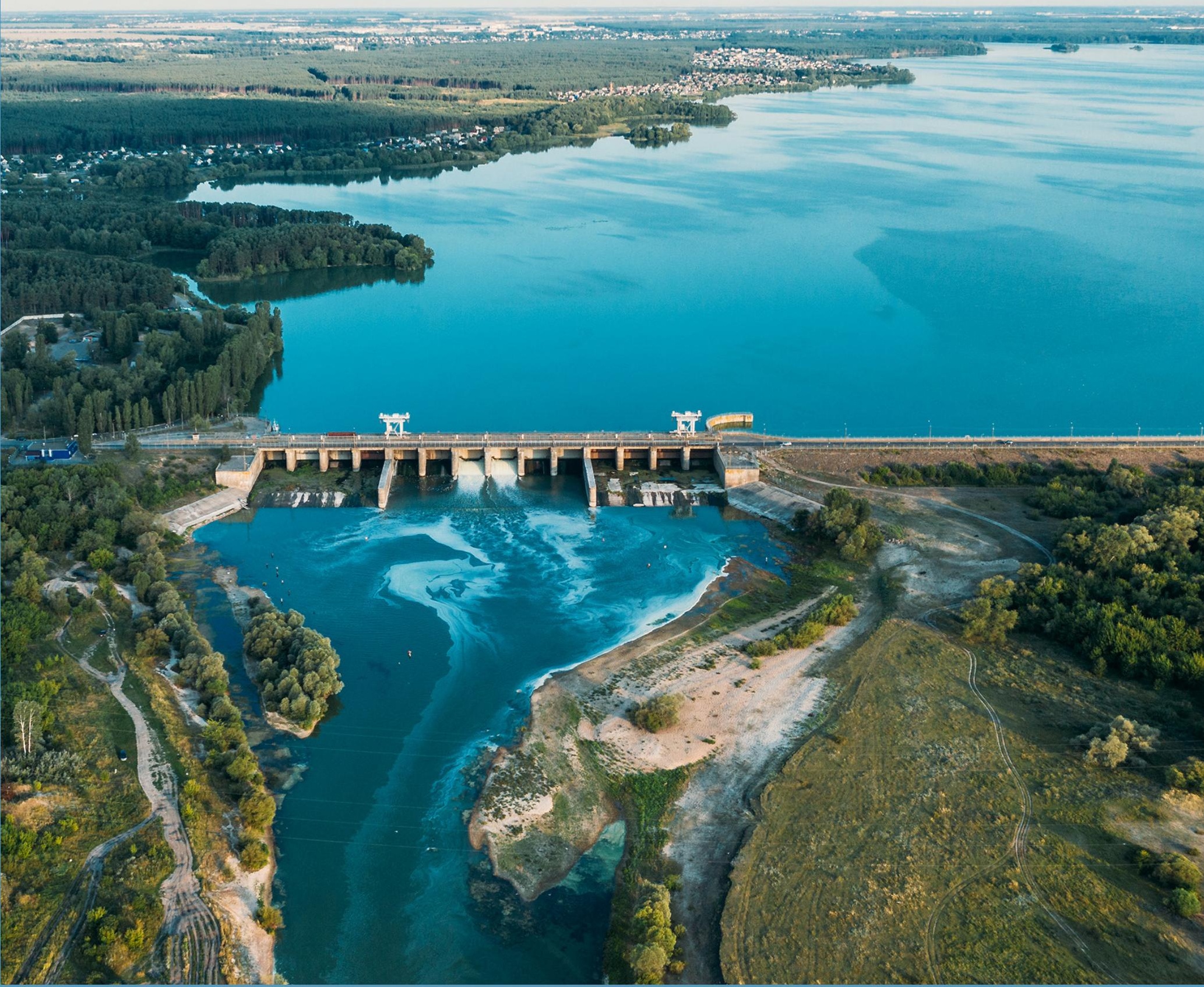

\section{Retrouvez toute la collection}

https://www.ifpenergiesnouvelles.fr/article/les-cahiers-leconomie

\section{if}

228 - 232 avenue Napoléon Bonaparte

92852 Rueil-Malmaison

www.ifpschool.com

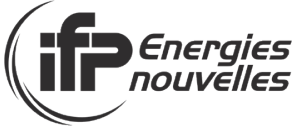

1-4 avenue de Bois-Préau

92852 Rueil-Malmaison

www.ifpenergiesnouvelles.fr 